\title{
The Follow up of the Anxiety Levels of Elderlies During the 'COVID-19' Pandemic: A Prospective Primary Care Study
}

\author{
Öznur Odabaş ${ }^{1}$, Ezgi Ağadayı ${ }^{2}$, and Duygu Ayhan Başer $^{3}$ \\ ${ }^{1}$ Ankara Bala Central Family Health Center \\ ${ }^{2}$ Sivas Cumhuriyet University Faculty of Health Sciences \\ ${ }^{3}$ Hacettepe University Faculty of Medicine
}

June 1, 2021

\begin{abstract}
Background: The COVID-19 outbreak quickly spread to hundreds of countries and became the first pandemic caused by coronaviruses. As the epidemic spread rate gradually increased in Turkey, curfews were imposed on individuals aged 65 and over as of March 21, 2020. We thought that both the pandemic and the curfew caused anxiety in the elderly. This study investigated the prevalence of anxiety symptoms by using Geriatric anxiety scale in the elderly during curfew. The change in anxiety level was measured over time. The second purpose of the study is to determine the factors affecting anxiety. Method: We evaluated older people's anxiety status with an interval of 15 days and 6 months during Covid-19 pandemic by using Geriatric anxiety scale. People aged 65 and over among the enrolled population of the FHC were contacted by telephone. Results: 250 people aged 65 and over were called by phone, 213 people were reached.150 people volunteered to participate in the study. While the mean scores of the first Geriatric anxiety scale were $1.0 \pm 2.4$, second score applied at the 15 th days was $0.5 \pm 2.1$, the third score applied at the sixth month was $0.3 \pm 1.8$. There was a significant difference between the three measurements $(\mathrm{p}=0.002)$. Conclusions: Total anxiety scores of our sample were low and there was a significant difference between the three measurements performed 15th days and sixth month was a decrease in anxiety. Contrary to what we expected, the elderly were not affected by curfew, and anxiety levels were found to be significantly decreased over time. Gender, education level, living alone, house type were found related with changes in anxiety scores.
\end{abstract}

\section{Hosted file}

The Follow up of the Anxiety Levels of Elderlies Ijcp.docx available at https://authorea.com/ users/417384/articles/524516-the-follow-up-of-the-anxiety-levels-of-elderlies-duringthe-covid-19-pandemic-a-prospective-primary-care-study

\section{Hosted file}

Figure.docx available at https://authorea.com/users/417384/articles/524516-the-follow-up-ofthe-anxiety-levels-of-elderlies-during-the-covid-19-pandemic-a-prospective-primary-carestudy 